\title{
Public Spheres in Interaction: Comment Sections of News Websites as Counterpublic Spaces
}

This is the accepted version of the article:

Toepfl, F., \& Piwoni, E. (2015). Public Spheres in Interaction: Comment Sections of News Websites as Counterpublic Spaces. Journal of Communication, 65(3), 465-488. http://doi.org/10.1111/jcom.12156

The definitive version is available at: http://onlinelibrary.wiley.com/doi/10.1111/jcom.12156/abstract

\author{
Florian Toepfl \\ Free University of Berlin \\ Eunike Piwoni \\ University of Goettingen
}

\section{Authors' Note}

Florian Toepfl, Institute for Media and Communication Studies, Free University of Berlin, Germany; Eunike Piwoni, Department of Sociology, University of Goettingen, Germany.

Correspondence concerning this article should be addressed to Florian Toepfl, Institute for Media and Communication Studies, Free University of Berlin, Garystrasse 55, 14195 Berlin, Germany. Email: f.toepfl@fu-berlin.de

\section{Acknowledgements}

This research was supported by a Marie Curie Intra-European Fellowship sponsored within the 7th Framework Program of the European Union (awarded to Florian Toepfl) and an Emmy Noether Fellowship sponsored by the German Research Foundation DFG (awarded to Florian Toepfl). 
RUNNING HEAD: PUBLIC SPHERES IN INTERACTION

\section{Abstract (maximum 120 words)}

Research scrutinizing political talk online has been developed largely against the backdrop of deliberative discursive norms and considered political talk without a systematic analysis of surrounding mass-mediated discourses. By contrast, this study operationalizes counterpublic theory as an alternative theoretical perspective and analyses comments on news websites as a reaction to hegemonic mainstream public spheres. It juxtaposes a qualitative framing analysis of all articles about a new anti-Euro party in devotedly pro-European Germany published on nine news websites in the week following the 2013 elections $(n=22)$ with a content analysis of all comments posted below these articles $(n=3154)$. It finds counterpublic spheres differently shaped in comment sections of right- and left-leaning, and tabloid and non-tabloid, outlets. Consequences for democracy are discussed.

Keywords: comment sections, counterpublics, participatory journalism, political communication, public sphere, Germany, content analysis, framing 
RUNNING HEAD: PUBLIC SPHERES IN INTERACTION

\section{Public Spheres in Interaction: Comment Sections of News Websites as Counterpublic Spaces}

As a range of recent research suggests, commenting on news articles is currently the most widely practiced form of audience participation on news websites across Western democracies (Domingo et al., 2008; Reich, 2011; Thurman, 2008). This striking popularity of comment sections with both news organizations and their audiences has recently spurred a growing number of academic studies (cf. Freelon, 2010, 2013; Nielsen, 2013; Ruiz et al., 2011; Weber, 2014). To date, however, as Freelon (2013) has pointed out, research that assesses the democratic consequences of political talk online has been developed almost exclusively against the normative backdrop of deliberative discursive norms, with the most common reference being Habermas's (1962/1989) early work on the public sphere (cf. also Eveland et al., 2011). To broaden this recently vibrant academic debate, Freelon (2013) suggests and operationalizes two further sets of measures against which political talk can be evaluated, from a liberal individualist and a communitarian normative perspective.

This study seeks to build upon and extend this strand of literature in at least three respects. Firstly, it proposes and operationalizes a further normative stance that can be adopted in order to analyse comments posted on news websites: that of counterpublic theory. Counterpublic theory is one of the most widely discussed normative positions in the theoretical literature on the affordances of "digital democracy" (Dahlberg, 2011). However, scholars have typically located counterpublics in communicative spaces outside the mass media, for instance in blogs, forums, or alternative online media outlets (Cammaerts, 2009; Dahlberg, 2011). By contrast, this study focuses on counterpublic discursive activities as they evolve on the platforms of opinion-leading mass media. Secondly, we make a pioneering attempt to suggest a set of measures for quantitatively determining the extent to which the comment sections of various mass-media outlets are permeated by different types of counterpublic element. And thirdly, previous research has scrutinized political talk online largely in isolation, 


\section{RUNNING HEAD: PUBLIC SPHERES IN INTERACTION}

that is, without a systematic, content-based analysis of surrounding mass-mediated discourses (cf. Boczkowski \& Mitchelstein, 2012; Diakopoulos \& Naaman, 2011; Freelon, 2013; Ruiz et al., 2011; Weber, 2014; Zhou et al., 2008). By contrast, this study focuses on the interaction of multiple but unequal public spheres, including that of opinion-leading online media.

To work towards these goals, we scrutinize the case of a newly founded anti-Euro party in devotedly pro-European Germany: the Alternative for Germany (Alternative für Deutschland, AfD). In the 2013 general elections, this new party won $4.7 \%$ of the vote. Only six months after its foundation, the AfD thus failed only by a small margin to scale the $5 \%$ hurdle for entering the German parliament. This article presents two types of analysis: it juxtaposes a qualitative framing analysis of all articles published about the AfD on nine opinion-leading news websites in the week following the elections $(n=22)$ with a content analysis of all comments posted below these articles $(n=3,154)$.

As our qualitative framing analysis shows, German mass-media discourse on this topic was hegemonic, in the sense that all news websites consentaneously framed the new party in ways that were strongly opposed by its supporters. Our quantitative content analysis of comment sections evidences how these were, conversely, dominated by supporters of the new anti-Euro party. Across all types of news website (both right- and left-leaning and both tabloid and non-tabloid), comments containing counterpublic elements predominated over mainstream comments. Counterpublic discourse was, however, more vibrant and extensive on right-leaning platforms. On broadsheet platforms, it was directed less towards strengthening the identity of the party by making emotional appeals and more towards an argumentative countering of the hegemonic consensus in mainstream media discourse.

The remainder of this article is organized as follows: in the next section, we review the extant literature on comment sections and digital counterpublics in order to develop a concise theoretical framework for our study. Rooted in this framework, we then specify our research goals and formulate the hypotheses for the content analysis. The following section details the 


\section{RUNNING HEAD: PUBLIC SPHERES IN INTERACTION}

methods adopted. We then present the results of our two types of analysis. In a concluding section, we discuss how our study advances, and links, the extant literatures on comment sections and digital counterpublics, and point to five promising directions for future research.

\section{Comment Sections as Novel Communicative Spaces}

The enormous popularity of comment sections has recently sparked intense interest among communications scholars across different fields. In journalism studies, a vibrant strand of research has emerged investigating how journalists have adapted, in their daily work routines and professional ethics, to the advent of user-generated comments (cf., for instance, Nielsen, 2013; Reich, 2011). The findings of these studies were ambiguous: while journalists appeared to cautiously welcome and embrace input from their readers, they were also often found to be sceptical about the quality and trustworthiness of user-generated content and, overall, to be eager to maintain "their jurisdiction over news content." (Nielsen, 2014, p. 470) In the field of audience research, although detailed statistical data are still rare (for an overview, see Ziegele \& Quiring, 2013), extant surveys indicate an increasing spread of comment sections across the globe. With regard to South Korea, Lee and Jang (2010) reported that as many as $84 \%$ of news users read comment postings at least once a week. For the USA, Diakopoulos and Naaman (2011) found in a case study of a local news website in California that $65 \%$ of its audience read comments "all the time" or "often." A nationally representative survey by the Pew Research Center yielded the information that $25 \%$ of American internet users had commented on a news story or blog item (Purcell et al., 2010).

In the adjacent field of media psychology, scholars have increasingly interrogated the effects of comment sections on news audiences (cf., for instance, Lee, 2012; Lee \& Jang, 2010). As these studies illustrate, user-generated comments can not only significantly impact readers' perceptions of public opinion, they can also change readers' personal opinions (Lee, 2012; Lee \& Jang, 2010). A related group of studies centres on the question of whether, and to what degree, certain characteristics of news items predict the intensity of commenting 


\section{RUNNING HEAD: PUBLIC SPHERES IN INTERACTION}

(Boczkowski \& Mitchelstein, 2012; Weber, 2014). Weber (2014), for instance, showed that the news factors of articles significantly impacted both participation and interactivity levels in the comment sections below them. A further group of studies has examined the social characteristics and motives of commenters on different platforms (Diakopoulos \& Naaman, 2011; Mitchelstein, 2011).

A cluster of works of particular relevance to this study has analysed the content published in comment sections (Al-Saggaf, 2006; Douai \& Nofal, 2012; McCluskey \& Hmielowski, 2011; Freelon, 2013; Ruiz et al., 2011; Zhou et al., 2008). As Freelon (2013; cf. also Eveland et al., 2011) has recently pointed out, the clearly dominant normative framework in studies evaluating discourse in comment sections is the model of a deliberative public sphere, with references to Habermas's (1962/1989) early work (e.g., Al-Saggaf, 2006; McCluskey \& Hmielowski, 2011; Ruiz et al., 2011; Zhou et al., 2008). The most extensive study of this type was conducted by Ruiz et al. (2011), who content analysed 15,000 comments harvested from five national newspapers across five democracies. A central goal of this study was to determine the degree to which these digital discussions complied with Habermas's principles for democratic debate. As Ruiz et al. (2011) found, the comment communities of two newspapers in Anglo-American countries (The Guardian, UK, and The New York Times, USA) were more in line with Habermasian ideals than those of three newspapers in non-Anglo-American countries (Le Monde, France, El País, Spain, and La Repubblica, Italy).

Going beyond Ruiz et al.'s (2011) focus on deliberative norms, Freelon (2013) has suggested two further normative frameworks for evaluating political debate online: communitarianism and liberal individualism. Moreover, Freelon (2013) has conducted a normative comparison across two technical platforms: Twitter hashtags and online newspapers' comment sections. One of his central conclusions was that issue hashtags on Twitter made the appearance of communitarian indicators more likely, while comment sections generated discourse that complied better with both deliberative and liberal individualistic norms. 


\section{RUNNING HEAD: PUBLIC SPHERES IN INTERACTION}

The present study builds upon and extends this strand of literature in at least two respects. Firstly, it suggests and operationalizes a further theoretical perspective against which the content of comment sections can be evaluated: that of counterpublic theory. Secondly, extant research has analysed political debate online largely in isolation, that is without a systematic, content-based analysis of mass-mediated discourse. By contrast, this study focuses on the interaction of public spheres in two communicative spaces. It combines a qualitative framing analysis of mainstream media discourse with a quantitative content analysis of usergenerated comments. The approach is thus based on the assumption that structural features of the content posted to comment sections on a specific issue can only be fully understood in connection with an analysis of the structural features of mass-media discourse on that issue.

\section{Counterpublic Theory and Counterpublics in the Digital Age}

The basis for much of the theoretical thinking on counterpublics in the discipline of communications (e.g. Asen, 2000; Breese, 2011; Downey \& Fenton, 2003; Dahlberg, 2011) was laid out by Fraser (1992) in her seminal essay aimed at Rethinking the Public Sphere. In this essay, Fraser (1992, p. 123) defined "subaltern counterpublics" as "parallel discursive arenas where members of subordinated social groups invent and circulate counterdiscourses to formulate oppositional interpretations of their identities, interests, and needs." She argued that counterpublics typically emerged in response to hegemonic "publics at large" (Fraser, 1992, p. 124). According to Fraser's (1992) account, the function of counterpublics within a democratic social order is thus to expand discursive space and to partly offset the "unjust participatory privileges enjoyed by members of dominant social groups." (p. 124)

A similar understanding of democracy was later widely referred to by scholars of counterpublics and developed as an "agonistic" (Mouffe, 1999) model of democracy (Dahlberg, 2007, 2011). Whereas theories of deliberative democracy are oriented towards the achievement of consensus through rational debate, the agonistic model is based on the fundamental premise that all democratic " "politics' consists in domesticating hostility" and is thus "always 


\section{RUNNING HEAD: PUBLIC SPHERES IN INTERACTION}

concerned with the creation of an 'us' by the determination of a 'them'." (Mouffe, 1999, pp. 754-5) In this model, the aim of democratic politics is hence not to bracket passions or group identities in order to render rational consensus possible, but to "mobilise those passions towards the promotion of democratic designs." (Mouffe, 1999, p. 756) In an agonistic model of democracy, counterpublics can take on important roles. They are by no means intended to be separatist or isolated enclaves of discourse. On the contrary, their central function is to engage in publicity and break up hegemonic consensual patterns within dominant publics (cf. also Asen, 2000, p. 429; Warner, 2002). The democratic task of feminist counterpublics, for instance, would be to transform the hegemonic structure of the public sphere at large into a new hegemonic structure incorporating feminist claims (Fraser, 1992; Mouffe, 1999).

In the two decades since the publication of Fraser's seminal essay, counterpublics have been analysed as they emerged in a variety of communicative spaces (for overviews of this literature, see Asen, 2000; Breese, 2011; Dahlberg, 2011). Since the rise of digital media in the 2000s, counterpublics have also been scrutinized in a range of novel communicative spaces, including, for instance, alternative online media websites, social networks, discussion forums, blogs, e-mail lists and self-broadcast video and audio clips (cf. Dahlberg, 2011, pp. 861-2; Downey \& Fenton, 2003; Cammaerts, 2009, 2012). However, within this literature counterpublics have typically been located outside the mass media, in alternative communicative spaces. By contrast, this study analyses counterpublic discourses as they evolve on the websites of opinion-leading mass media outlets.

\section{Clarifying Key Concepts: Three Criteria for Distinguishing Public Spheres}

To work towards this goal, we develop in this section the theoretical framework of the study. We do so by defining a series of key concepts as we propose to understand these for the purposes of our analysis. In line with the majority of recent theoretical accounts of the public sphere (cf. Asen, 2000; Breese, 2011; Lunt \& Livingstone, 2013; Dahlberg, 2005; Dahlgren, 2007), we conceive of the overarching public sphere of a polity - the "public sphere at large" 


\section{RUNNING HEAD: PUBLIC SPHERES IN INTERACTION}

(Fraser, 1992, p. 124) - as being comprised of a multiplicity of unequal (sub-)public spheres.

We suggest that each of these sub-public spheres can be delimited by researchers, for heuristic purposes, in terms of a combination of required characteristics relating to three criteria (cf. Asen, 2010; Dahlgren, 2005; Fraser, 1992; Warner, 2002):

(1) the communicative spaces within which a public sphere operates (e.g. the mass media, alternative media, salons, online forums, or protest meetings);

(2) the common discursive patterns that distinguish a public sphere (e.g. deliberative discursive norms in the Habermasian tradition, or the awareness of exclusion in counterpublic theory, cf. Asen, 2000); and

(3) the participants who constitute a public sphere, both as speakers and as attentive audiences (e.g. journalists, readers, members of minorities, or activists, see Warner, 2002). In this article, we employ these three criteria in order to analytically distinguish a variety of (sub-)public spheres, which we subsequently juxtapose. For instance, we locate a first public sphere in the news article sections of Germany's opinion-leading mass-media websites (communicative space). Here, professional journalists, as gatekeepers, present statements mainly of the leaders of major parties and non-governmental organizations, and of experts; their audience is a mass audience comprised largely of politically interested citizens including societal elites (participants). In presenting this content, journalists follow specific professional norms such as objectivity and fact checking, and they adopt specific forms of, largely nonemotional, speech (discursive patterns). Within the German public sphere at large, this is arguably one of the most powerful public spheres, since it is widely received amongst the country's elites and can thus be considered as having considerable impact on the formation of political will (Arbeitsgemeinschaft Online Forschung [AGOF], 2013).

We identify as analytically separate from this first public sphere a second public sphere in the comment sections of these news websites (communicative space). Here, ordinary citizens can publish their statements, while journalists act merely as moderators and censors; 


\section{RUNNING HEAD: PUBLIC SPHERES IN INTERACTION}

even though the audience is only a fraction of the audience of our first sphere (Diakopoulos \& Naaman, 2011; Lee \& Jang, 2010; Ziegele \& Quiring, 2013), it is still a mass audience of politically interested citizens (participants). In comment sections, political discourse is typically less standardized and more emotional than in journalistic articles, but moderators impose limits on certain types of uncivil talk (discursive patterns; cf. Ruiz et al., 2011). By comparison with the news article sections of online media, this sphere is much weaker, since it features less respected speakers and a much smaller, less influential audience. However, it can still be considered far more powerful than other (sub-)public spheres operating, for instance, in issuespecific forums, on blogs or on alternative news websites - spaces that typically have a yet much smaller and much less diverse audience.

For heuristic purposes, we divide this second public sphere of comment sections further into different sub spheres. To do so, we use the three criteria introduced above (spaces, discursive patterns, and participants). For instance, on the basis of the criteria of spaces and participants, we distinguish as two distinct sub-public spheres the comment sections of left- and of right-leaning websites. Using the same criteria, we also juxtapose the comment sections of tabloid and non-tabloid websites. Nested within each of these public spheres, we additionally delimit two further sub-public spheres, using the criterion of "counterpublic" discursive patterns: a mainstream and a counterpublic sphere. By counterpublic discursive patterns, or counterpublic discourse, we understand talk that

(1) sets itself off from a superordinate public sphere which it explicitly deconstructs as being mainstream and dominant (deconstructing power relations, cf. Asen, 2000; Downey \& Fenton, 2003); or

(2) puts forward arguments that challenge the consensus of this superordinate public sphere (providing counterarguments, cf. Fraser, 1992; Warner, 2002); or

(3) seeks to strengthen a sense of collective identity amongst the supporters of the subordinate public sphere (strengthening identity, cf. Dahlberg, 2011; Fraser, 1992) 


\section{RUNNING HEAD: PUBLIC SPHERES IN INTERACTION}

Starting out from this definition of counterpublic talk, we shall refer to individuals or groups who support such talk as counterpublic-minded individuals or groups, to individuals who produce such talk in comment sections as counterpublic commenters, to communicative spaces dominated by such talk as counterpublic spaces, and to the ideas that such talk communicates in a specific socio-political context as counterpublic ideas or arguments. In line with public sphere theorists who advocate contestationary models of democracy (cf. Dahlgren, 2005; Dahlberg, 2007; Fraser, 1992; Mouffe, 1999), and in contrast to research in the Habermasian tradition, we thus do not regard rational discursive patterns to be a constitutive criterion for any "public sphere.” In a less exigent definition, we consider communicative spheres to be "public" spheres (1) if they aim to impact the formation of the political will of a polity and (2) if there is, as Dahlgren (2005) put it, at least "some semblance of impact" (p. 152) on political decision-making (cf. also Fraser, 1992; Warner, 2002).

\section{Research Aims and Hypotheses: Comment Sections as Counterpublic Spaces}

Grounded in this theoretical framework, our assumption is that the typical configuration of the comment sections of news websites in Western democracies as public spheres (i.e. in terms of space, participants, and discursive patterns) is highly conducive to the emergence of (sub-)counterpublic spheres within those. We have one main reason for assuming this: comment sections as public spheres provide counterpublic-minded individuals with excellent opportunities to pursue transformative aims in relation to the public at large. This is firstly because, in contrast to discussion fora, social networks, or alternative media sites, comment sections are hosted on the platforms of mass-media outlets (space) and are therefore highly visible to members of the mainstream public (participants, cf. Diakopoulos \& Naaman, 2011; Lee \& Jang, 2010; Purcell et al., 2010; Ziegele \& Quiring, 2013). Secondly, by comparison with "letters to the editor," an earlier and closely related format, more citizens can publish their statements (participants), with gatekeeping journalists typically allowing a much wider range of ideas and expressive forms to be published (discursive patterns, cf. McCluskey \& 


\section{RUNNING HEAD: PUBLIC SPHERES IN INTERACTION}

Hmielowski, 2011; Ruiz et al., 2011). Thirdly, in comment sections, counterarguments can be posted in the immediate spatial vicinity (space) of specific hegemonic ideas as these are formulated in the mainstream public sphere. For these three reasons, at least, the comment sections of news websites can be considered a uniquely configured public sphere, standing out from the multiplicity of public spheres that constitute publics at large in today's digital democracies. Counterpublic-minded individuals can therefore be expected to have extraordinarily strong incentives to take discursive action in these rather particular public spheres, that is to author counterpublic comments, to "like" other counterpublic comments, or to respond critically to mainstream comments.

On the basis of these reflections, we suggest a number of hypotheses that we expect to be valid in communicative situations, in which mass media discourse in democratic societies systematically disregards the views of a vocal minority on a specific issue. We assume that, in such circumstances, comment sections will contain significantly more counterpublic elements than one would expect, given (a) the absence of these ideas from mainstream discourse and (b) the minority status of the marginalized group (H1). With regard to our case study, we know, for instance, that less than $5 \%$ of the German electorate voted for the new anti-Euro party immediately before the time period of our analysis. Moreover, as our qualitative framing analysis shows, counterpublic ideas supporting the new party were largely absent from mainstream media discourse. Hence, we suggest considering $\mathrm{H} 1$ as broadly confirmed if more than $50 \%$ of the comments contain counterpublic elements supporting the AfD (H1a). Further fleshing out $\mathrm{H} 1$ by adding two additional sub-theses, we also posit that counterpublic comments will attract more "likes" than mainstream comments (H1b); and that counterpublic comments will receive fewer oppositional responses than mainstream comments (H1c).

Our second cluster of hypotheses investigates differences between the comment sections of right- and left-leaning websites as two distinct public spheres. As our qualitative framing analysis evidences, the news article sections of both right- and left-leaning newspapers can be 


\section{RUNNING HEAD: PUBLIC SPHERES IN INTERACTION}

considered to be part of the mainstream public sphere, since counterpublic ideas were largely absent from journalistic coverage about the AfD in both types of mass-media outlet. Nonetheless, we expect the configuration of the comment sections of right-leaning newspapers as public spheres (in terms of spaces, discursive patterns, and participants) to be slightly more conducive to the emergence of a pro-AfD (sub-)counterpublic sphere within those. In German mass-media discourse, the AfD has been widely viewed as situated on the far right of the political spectrum. We can thus assume (1) that amongst the regular readers of right-leaning platforms, the proportion of AfD supporters as potential commenters was slightly higher (participants); and (2) that, partly following from our first assumption, supporters of the pro-AfD counterpublic might have expected that the hegemonic consensus of the mainstream public sphere could more easily be broken up and transformed on right-leaning platforms. On the basis of these considerations, we posit that (pro-AfD) counterpublic comments will be more numerous in the comment sections of right-leaning websites $(\mathrm{H} 2 \mathrm{a})$ and that, in absolute numbers, significantly more counterpublic comments will appear on right-leaning rather than leftleaning websites (H2b). Furthermore, we explore the open research question of whether different elements of counterpublic discourse prevail on left- or on right-leaning platforms (RQ1).

Our third type of hypothesis concerns differences between the comment sections of tabloid and non-tabloid websites, which we again conceive of as two differently configured public spheres. Previous research suggests that the comment sections of news websites vary widely in terms of levels of impoliteness and derogatory references (Ruiz et al., 2011). To our knowledge, however, no empirical study has specifically investigated differences between discursive patterns in the comment sections of tabloid and non-tabloid websites. We assume, however, that widely acknowledged key differences between these two types of media outlet will also be reflected in the counterpublic spheres that emerge in their comment sections. Specifically, we posit that: on broadsheet websites, counterpublic comments will rely more on 
RUNNING HEAD: PUBLIC SPHERES IN INTERACTION

counter-argumentation (H3a); and that on tabloid websites, counterpublic comments will rely more on emotional appeals (H3b). Moreover, we explore the question of whether different elements of counterpublic discourse prevail on tabloid and on non-tabloid websites (RQ2).

\section{Methods}

\section{Qualitative Framing Analysis of Mainstream Discourse}

The goal of our first type of analysis was to map the hegemonic pattern of consensus concerning the AfD in the mainstream public sphere of Germany's opinion-leading online mass media in the week following the 2013 general elections (22-29 September 2013). To do so, we selected nine opinion-leading German news websites for analysis. We selected these nine outlets on the basis partly of audience data (AGOF, 2013) and partly of our cultural knowledge about the centrality of different outlets to the formation of political opinion in Germany. By the latter criterion, we excluded from the analysis, for instance, some highly frequented websites that redistributed small bites of political news, such as the webmail portals Yahoo.de or Web.de. Conversely, we included online newspapers with relatively small but politically active audiences such as taz.de, which is known to be a national forum of debate for the German Left. Using these criteria, we arrived at the following selection of news websites: bild.de, faz.net, welt.de and focus.de (right-leaning); and sueddeutsche.de, spiegel.de, zeit.de, fr-online.de and taz.de (left-leaning). All nine websites are the online versions of highly influential German print-media titles. The selection also included bild.de as the online version of Germany's only tabloid of national importance. In terms of audience reach (AGOF, 2013), the sample ranked as follows: bild.de (6.59 million unique users per average week in the third quarter of 2013), spiegel.de (5.19), focus.de (3.44), welt.de (3.12), sueddeutsche.de (2.65), zeit.de (1.97), faz.net (1.46), fr-online.de (0.49), and taz.de (0.42).

On these nine websites, we conducted keyword searches for the party's name ("AfD” and "Alternative für Deutschland"). We included in our analysis all articles that devoted more than half of their content to the new party $(n=22)$. In order to analytically capture the funda- 


\section{RUNNING HEAD: PUBLIC SPHERES IN INTERACTION}

mental patterns of consensus as they underlay the comprehensive reporting of the AfD in this mainstream public sphere, we conducted a qualitative framing analysis, broadly following a grounded theory approach (for a detailed discussion of how to adopt this approach in framing research, consider Van Gorp, 2010). Thus, we repeatedly read and reread the articles, using the constant comparative method. In a first step of open coding, we identified dozens of idea elements. We then regrouped and made sense of these idea elements using axial and selective coding. As a result, we obtained a portrayal of the consensus structure within our text corpus that featured two types of frame at two levels. At a first level, we identified seven frames that can be best understood as "emphasis frames" (De Vreese, 2010, p. 189). As De Vreese (2010, p. 189) has argued, emphasis frames "suggest that different aspects of an issue can be emphasized;" they are "alternative ways of defining issues." For example, when "thinking about oil drilling, citizens may be presented with [emphasis] frames of reference such as gas prices, unemployment, environment, or U.S. dependency on foreign energy sources." (De Vreese, 2010, p. 189) In a similar vein, we identified in our case study seven emphasis frames, within which journalists suggested thinking about the electoral success of the AfD. These included, for instance, the questions of how to situate the new party within the established German party system (party label), or how to evaluate the quality of the party's manifesto (party manifesto). At a second level, we found that, within each of these seven emphasis frames, a limited range of idea elements was employed to characterize the party. For instance, within the emphasis frame party label, journalistic texts largely referred to the AfD as a right-wing, protest or populist party. These idea elements are best understood as "issue-sensitive" (De Vreese, 2010, p. 189) or issue-specific news frames, since they make sense only with regard to this specific issue. As a result of our qualitative framing analysis, we thus obtained (a) seven emphasis frames and (b) within each of these emphasis frames a comprehensive range of issuespecific frames as they occurred in our text corpus. We consider this two-tiered structure of frames to be the hegemonic consensus pattern that underlay the reporting of the AfD's elec- 
RUNNING HEAD: PUBLIC SPHERES IN INTERACTION

toral success in the mainstream public sphere.

\section{Quantitative Content Analysis of Comments Posted}

Sampling. As a second type of analysis, we conducted a quantitative content analysis of all comments $(n=3,154)$ posted on the 22 articles included in our qualitative framing analysis. Our data set was structured as follows: welt.de (4 articles, 823 comments), faz.net $(5,1019)$, bild.de (3, 456), focus.de (1, 154), spiegel.de (1, 234), sueddeutsche.de (4, 271), zeit.de (1, 158), fr-online.de $(2,14)$, taz.de $(1,25)$.

Measures. Drawing on the theoretical literature on counterpublics (cf. Introduction), we used three widely discussed characteristics of counterpublics to develop our coding scheme. We considered a comment to be part of the counterpublic if it:

(1) countered the mainstream media consensus within one of our seven emphasis frames by providing alternative issue-specific frames that were not present in the mainstream media (argumentative countering); or

(2) strengthened the collective identity of party supporters by making a statement of personal identification or by employing emotional statements (strengthening identity); or

(3) explicitly pointed to firmly consolidated power relationships within the media, politics or society as allegedly working against the AfD (deconstructing power relationships).

With regard to the first criterion, we thus developed our coding scheme drawing on the two-tiered set of frames that emerged from our qualitative framing analysis (cf. Results section). For instance, within the emphasis frame party label, mainstream news websites assigned almost exclusively dismissive labels to the party, locating it outside the legitimate party spectrum. They referred to the AfD as a "right-wing", "protest" or "populist" party (issuespecific frames). Consequently, we coded a comment as countering the consensus within mass-media discourse if it explicitly rejected one of these labels and suggested an alternative label for the party, for instance "democratic" or "liberal." The full details of our coding scheme, including sample comments for each category and key words used as indicators can 


\section{RUNNING HEAD: PUBLIC SPHERES IN INTERACTION}

be found in the codebook uploaded as an online file supplementary to this article.

Within the second category (strengthening identity), we coded a comment as emotional if it contained any marker signalling emotional involvement in favour of the AfD (for example, "thank God", “disappointing”, "unfortunately”) or even stronger markers of sarcasm, or cynicism (subcategory: emotional involvement). We coded a comment as containing impolite speech if the statement would have been unthinkable on a political talk show on public TV (subcategory: impolite tone). We coded a comment as containing a statement of personal identification if the commenter used the pronouns "I" or "we" when speaking of the AfD or if they stated explicitly that they had voted for the new party (subcategory: personal identification).

Within Category 3 (deconstructing power relationships), we coded a comment if the commenter, for instance, stated that German public television was "government-controlled state television lacking objectivity" (subcategory: mass media); or that amongst political elites "opinions critical of the EU were clearly a taboo" (subcategory: political establishment); or if the commenter suspected that the elections had been rigged to prevent the AfD from entering parliament (subcategory: electoral fraud); or if the commenter made a nonattributable statement about power relations working against the AfD (subcategory: unspecified). We thus arrived at a set of 14 binary variables, indicating the presence or absence $(1 / 0)$ of 14 specific counterpublic elements for each comment in our data set.

Coding process, reliability, and statistical significance. After conducting several pilot reliability tests and refining our codebook each time, the two authors of this study carried out the coding of the data set. A random sample of approximately $10 \%(\mathrm{n}=319)$ of comments was coded by each of the coders. A reliability test resulted in the following, either largely or highly satisfactory percentages of agreement and values for Scott's pi (cf. Neuendorf, 2002, pp. 141-166): counterpublic comment ( $96 \%$ agreement, $\pi=.90)$, mainstream comment $(96 \%$, $\pi=.88)$, off-topic comment $(98 \%, \pi=.76)$, personal identification $(99 \%, \pi=.91)$, emotional 
RUNNING HEAD: PUBLIC SPHERES IN INTERACTION

statement $(85 \%, \pi=.71)$, counterargument within the emphasis frames party label $(94 \%$, $\pi=.83)$, party leadership $(96 \%, \pi=.81)$, party electorate $(98 \%, \pi=.81)$, immigration policy $(97 \%, \pi=.79)$, EU policy $(95 \%, \pi=.87)$, party manifesto $(99 \%, \pi=.81)$, other policies $(98 \%$, $\pi=.71)$, deconstructing power relationships within the media $(98 \%, \pi=.92)$, within the political establishment ( $98 \%, \pi=.81)$, by assuming electoral fraud $(99 \%, \pi=.83)$. It was possible to achieve these high percentages of agreement because we worked with a rather elaborate, highly issue-specific codebook that contained not only indicative keywords for all variables but also sample comments. In addition, most variables were rather straightforwardly identifiable. For instance, whether or not a commenter referred to the party's manifesto was a rather clearcut coding decision.

Even though our data set can be viewed as a census of all comments posted in a particular case study, we report levels of statistical significance at some points in our argument. We do this on the basis of the alternative view that the appearance of a comment containing a specific counterpublic element (1/0) can be likened to a binomial random experiment, similar to tossing a toin. Within this framework, we use z-tests for comparing two proportions in order to calculate $p$-values of statistical significance. By doing this, we estimate the likelihood that our results concerning the differences between various sub-public spheres (tabloid and nontabloid, right- and left-leaning platforms) could have been obtained by chance.

\section{Results}

\section{Qualitative Framing Analysis of Mainstream Media Discourse}

In this section, we present seven emphasis frames within which the mainstream public sphere suggested thinking about the surprising electoral success of the AfD. Within each of these emphasis frames, we report a number of issue-specific frames as they were most widely adopted in our text corpus of 22 articles.

(1) Party label (identified in 20 of 22 articles). Within this first and most common emphasis frame, journalistic texts discussed the question of how to label the new party appropriate- 
RUNNING HEAD: PUBLIC SPHERES IN INTERACTION

ly. The AfD was most typically referred to as a "protest," "populist," or "right-wing" party (issue-specific frames), that is as not a legitimate addition to the party system.

(2) European Union/Euro policies (20 articles). This was a second emphasis frame within which the emergence of the new party was widely debated. At the subordinate level of issue specific frames, the most widely employed frames were that the AfD was hostile to the European Union and that it could only offer simplistic solutions to the Euro crisis.

(3) Party electorate (18 articles). Within this frame, journalists focused on the composition of the party's electorate. Issue-specific frames here were that the party had predominantly attracted "protest voters" and voters who had formerly voted for right-wing parties.

(4) Party leadership (15 articles). This fourth emphasis frame focused the debate on the party's leadership. The most common issue-specific frames here were that the party leadership was made up of populists with poorly conceived political ideas that bordered on right-wing extremism. For example, journalists found the language of party leader Bernd Lucke inappropriate and reminiscent of Nazi jargon. They pointed out that Lucke had spoken of "Entartungen der Demokratie" (degenerations of democracy) — a term that reminds Germans of the Third Reich term "entartete Kunst" (degenerate art).

(5) Immigration policy (14 articles). This emphasis frame centred the discussion on the party's ideas on immigration policy. Widely used issue-specific frames here were that the party slogans were discriminatory towards migrants and employed a populist language.

(6) Party manifesto (7 articles). Within this emphasis frame journalists examined the party's manifesto. The most widely employed issue-specific frames here were that the party programme was very short, not very detailed, and that it neglected pertinent questions.

(7) Other policies (11 articles). While the first six emphasis frames were the most salient in our corpus, some articles also discussed the emergence of the new party with reference to other AfD policies such as those on taxation, the regulation of the labour market, and family benefits. Within this seventh group of emphasis frames, issue-specific frames suggest- 
RUNNING HEAD: PUBLIC SPHERES IN INTERACTION

ed broadly that all these policies were either populist or ill-conceived.

With regard to the issue-specific frames, as we have sketched those in a few sentences for each emphasis frame, it is important to note that this portrayal is certainly pointed. Within the 22 articles, there were a small number of statements that deviated from the consensus pattern as set out here. The most deviant of the 22 articles appeared on the right-leaning news website faz.net. This article argued for instance, within the emphasis frame European Union policies, that the AfD had the potential to become a party of "economic reason". These exceptions notwithstanding, the patterns of consensus as sketched above were clearly dominant in our text corpus. Our framing analysis thus reveals the broad lines of a mass-media discourse that painted, consentaneously, a rather dismissive picture of the new anti-Euro party.

\section{Quantitative Content Analysis of Comment Sections}

In our sample of 3,154 comments posted on the 22 articles, we identified 2,342 comments (74.3\%) as being part of a (sub-)counterpublic sphere. These comments either

(1) countered issue-specific frames within one of the seven emphasis frames that were also present in the mass-media discourse $(52.3 \%, 1,648$ comments $)$, or

(2) claimed that power relationships within the sphere of media or politics were systematically disadvantaging the new party $(28.1 \%, 886$ comments $)$, or

(3) contained statements that strengthened the collective identity of party supporters $(50.1 \%$, 1,579 comments).

Within our data set, only 723 comments $(22.9 \%)$ did not contain any of these three types of element of counterpublic discourse. We will refer to these comments in the following as "mainstream comments," and think of them as a mainstream (sub-)public sphere. A mere 89 comments $(2.8 \%)$ had to be coded as incomprehensible or off-topic, in the sense that the coders could not identify whether the author aimed to counter or to support the mainstream media discourse. This latter finding illustrates the high degree to which political debate in comment sections was both antagonistic to the mainstream media discourse and focused on 


\section{RUNNING HEAD: PUBLIC SPHERES IN INTERACTION}

the central issue of the emergence of the new party. We thus found hypothesis H1a to be clearly confirmed: comments containing counterpublic elements clearly outnumbered comments endorsing the mainstream media discourse.

In H1b, we presumed that counterpublic comments would be "liked" more frequently than mainstream comments. To test this hypothesis, we had to narrow our analytical focus to the five websites that offered users the opportunity to "like" comments. Across these five platforms, counterpublic comments received substantially more likes than mainstream comments. On welt.de, for instance, mainstream comments received on average 9 likes, whereas counterpublic comments received on average 115 likes. Counterpublic comments were thus liked 12.8 times more frequently than mainstream comments. On faz.net, counterpublic comments were liked 8.2 times more frequently. Similarly, counterpublic comments were liked 6.0 times more frequently on sueddeutsche.net, 5.3 times more frequently on bild.de, and 1.2 times more frequently on zeit.de. We thus found strong support for H1b. Our third hypothesis, H1c, assumed that mainstream comments would generate more oppositional responses than counterpublic comments. In our data set, mainstream comments received $80.2 \%$ oppositional responses (e.g. counterpublic comments; $\mathrm{n}=503$ ). By contrast, counterpublic comment generated only $33.7 \%$ oppositional responses (e.g. mainstream comments; $n=362$ ). Our data thus clearly also endorses H1c.

In $\mathrm{H} 2 \mathrm{a}$, we assumed that different types of counterpublic would emerge on news websites of distinct political orientations. More specifically, we posited that counterpublic comments (supporting the anti-Euro party) would be relatively more dominant on right-leaning, by comparison with left-leaning, news sites. To test this hypothesis, we separated our selection of platforms into right-leaning websites (welt.de, faz.net, bild.de, and focus.de) and leftleaning websites (zeit.de, spiegel.de, sueddeutsche.de, fr-online.de, and taz.de). The percentage of counterpublic comments on our nine websites decreased in the following order: faz.net (85.3\%), welt.de (75.2\%), focus.de (74.0\%), sueddeutsche.de, $(65.7 \%)$, bild.de (65.4\%), spie- 
RUNNING HEAD: PUBLIC SPHERES IN INTERACTION

gel-online.de (64.1\%), zeit.de (57.6\%), and taz.de (52.0\%). On average, counterpublic comments represented $77.5 \%$ of all comments on right-leaning websites, but only $63.0 \%$ of all comments on left-leaning websites. The proportion of counterpublic comments was thus $14.5 \%$ higher on right-leaning newspapers $(p<.001)$. Our data hence strongly support H2a. $\mathrm{H} 2 \mathrm{~b}$ posited that, overall, comments on right-leaning platforms would be far more vibrant and extensive than on left-leaning outlets. In line with this hypothesis, an overwhelming majority of $77.7 \%(n=2452)$ of the comments in our sample were posted on the four rightleaning websites. By contrast, only $22.3 \%(n=702)$ were posted on the five left-leaning outlets. This difference in numbers appears to be partly due to the fact that the five left-leaning outlets decided to dedicate only nine articles to the AfD, while the four right-leaning outlets published 13 articles. Germany's right-leaning outlets thus provided more virtual space for pro-AfD counterpublics to emerge than did the left-leaning outlets. In addition, however, articles on right-leaning outlets received on average far more comments (189) than did articles on left-leaning websites (78). Thus, hypothesis $2 \mathrm{~b}$ is also confirmed. 


\section{RUNNING HEAD: PUBLIC SPHERES IN INTERACTION}

Table 1

Counterpublic discourses in comment sections of left- and right-leaning broadsheet news sites

\begin{tabular}{|c|c|c|c|}
\hline & \multicolumn{2}{|c|}{$\begin{array}{c}\text { Proportion of total of } \\
\text { counterpublic comments on }\end{array}$} & \multirow[b]{2}{*}{$\begin{array}{l}\text { Difference } \\
\text { in \% points }\end{array}$} \\
\hline & $\begin{array}{c}\text { left-leaning } \\
\text { websites } \\
(\mathrm{n}=442)\end{array}$ & $\begin{array}{c}\text { right-leaning } \\
\text { websites } \\
(n=1,900)\end{array}$ & \\
\hline ...containing counterarguments & $72.2 \%$ & $66.8 \%$ & $5.4^{*}$ \\
\hline Party label & $26.9 \%$ & $27.9 \%$ & -1.0 \\
\hline Party leadership & $12.9 \%$ & $16.3 \%$ & $-3.4^{*}$ \\
\hline Party electorate & $10.6 \%$ & $7.9 \%$ & $2.8^{*}$ \\
\hline Party's immigration policy & $8.1 \%$ & $9.1 \%$ & -0.9 \\
\hline Party's European policy & $43.4 \%$ & $33.0 \%$ & $10.4^{* *}$ \\
\hline Party manifesto & $5.0 \%$ & $3.4 \%$ & 1.6 \\
\hline ...strengthening identity & $69.0 \%$ & $64.2 \%$ & $4.8^{*}$ \\
\hline Personal identification & $10.0 \%$ & $6.6 \%$ & $3.4^{* * *}$ \\
\hline Emotional statement & $66.7 \%$ & $62.7 \%$ & 4.0 \\
\hline Impolite tone & $14.9 \%$ & $10.5 \%$ & $4.4^{* *}$ \\
\hline ...deconstructing power relations & $38.0 \%$ & $38.8 \%$ & -0.8 \\
\hline Mass media & $27.8 \%$ & $22.2 \%$ & $5.7^{* *}$ \\
\hline Political establishment & $5.2 \%$ & $7.1 \%$ & -1.9 \\
\hline Electoral fraud & $2.3 \%$ & $2.2 \%$ & 0.0 \\
\hline
\end{tabular}

$p<.05 .{ }^{* * *} p<.01$. (As calculated using a Z-statistic, for details see Method section) 
RUNNING HEAD: PUBLIC SPHERES IN INTERACTION

Did our data also reveal striking differences between the internal structures of counterpublic discourse on right- and on left-leaning platforms (RQ1)? As Table 1 illustrates, the internal structure of counterpublic discourse, as captured by our variables, was surprisingly similar on both right- and left-leaning platforms. On non-tabloid websites of both political orientations, counterpublic commenters challenged media discourse with approximately the same frequency within each of the seven emphasis frames. They also resorted with similar frequency to each of the three strategies for strengthening the identity of the counterpublic and to each of the three distinct ways of deconstructing power relationships. With the exception of the code "European policy," differences in proportion for all variables were below 6\%.

In our two final hypotheses, $\mathrm{H} 3 \mathrm{a}$ and $\mathrm{H} 3 \mathrm{~b}$, we turned to differences between tabloid and non-tabloid platforms. To do this, we analytically separated our data set into comments posted on Germany's only tabloid news website of national importance, bild.de, and comments posted on the remaining eight websites. The results of this analysis are depicted in Table 2. As Table 2 shows, counterpublic comments on the tabloid website relied much less on counterargumentation than did those on the broadsheet-affiliated platforms. On the tabloid site bild.de, only $38.6 \%$ of counterpublic comments contained a counter-argument. By contrast, this figure was $68.0 \%$ across the other platforms (difference: 29.4 percentage points, $p<$ $.001)$. Hypothesis 3 a was thus clearly confirmed. Moreover, our findings also endorsed hypothesis 3b. Counterpublic discourse on the tabloid website relied more on emotional appeals. On bild.de, $79.9 \%$ of counterpublic comments contained emotional statements, by comparison with only $63.6 \%$ for broadsheet-affiliated platforms. A particularly impolite tone was nearly twice as common in the comment section of the tabloid platform $(20.5 \%$ vs. $11.5 \%, p<.001)$. Aside from the associations tested in $\mathrm{H} 3 \mathrm{a}$ and $\mathrm{H} 3 \mathrm{~b}$, did our data point to further structural differences between counterpublic discourse on tabloid and on non-tabloid websites (RQ2)? Overall, we observed no striking differences in the frequency with which power relations were deconstructed (38.6 \% vs. $32.2 \%$ ). However, within this category there was one variable 


\section{RUNNING HEAD: PUBLIC SPHERES IN INTERACTION}

that differed remarkably: on the tabloid website, $11.7 \%$ of commenters suspected some form of electoral fraud against the AfD. Such conjectures were largely absent on the non-tabloid platforms (2.3\%; difference: 9.5 percentage points, $p<.001)$.

\section{Table 2}

Counterpublic discourses in comment sections of tabloid and non-tabloid news sites

\begin{tabular}{|c|c|c|c|}
\hline & \multicolumn{2}{|c|}{$\begin{array}{l}\text { Percentage of counterpublic } \\
\text { comments posted on }\end{array}$} & \multirow[b]{2}{*}{$\begin{array}{l}\text { Difference } \\
\text { in \% points }\end{array}$} \\
\hline & $\begin{array}{c}\text { Non-tabloid } \\
\text { outlets } \\
(n=2,044)\end{array}$ & $\begin{array}{l}\text { tabloid } \\
\text { bild.de } \\
(\mathrm{n}=298)\end{array}$ & \\
\hline ...containing counterarguments & $68.0 \%$ & $38.6 \%$ & $29.4^{* *}$ \\
\hline Party label & $27.7 \%$ & $8.7 \%$ & $19.0^{* *}$ \\
\hline Party leadership & $15.6 \%$ & $3.4 \%$ & $12.2^{* *}$ \\
\hline Party electorate & $8.5 \%$ & $3.0 \%$ & $5.4^{* *}$ \\
\hline Party's immigration policy & $8.9 \%$ & $1.0 \%$ & $7.8^{* *}$ \\
\hline Party's European policy & $35.3 \%$ & $26.2 \%$ & $9.1^{* *}$ \\
\hline Party manifesto & $3.7 \%$ & $2.0 \%$ & 1.7 \\
\hline ...strengthening identity & $65.2 \%$ & $81.2 \%$ & $-16.0^{* *}$ \\
\hline Personal identification & $7.3 \%$ & $4.7 \%$ & 2.6 \\
\hline Emotional statement & $63.6 \%$ & $79.9 \%$ & $-16.3^{* *}$ \\
\hline Impolite tone & $11.5 \%$ & $20.5 \%$ & $-9.0^{* *}$ \\
\hline ...deconstructing power relations & $38.6 \%$ & $32.2 \%$ & $6.4^{* *}$ \\
\hline Mass media & $23.4 \%$ & $17.8 \%$ & $5.6^{*}$ \\
\hline Political establishment & $6.7 \%$ & $4.0 \%$ & $2.6^{*}$ \\
\hline Electoral fraud & $2.3 \%$ & $11.7 \%$ & $-9.5^{* *}$ \\
\hline
\end{tabular}

$p<.05 .{ }^{* * *} p<.01$. (As calculated using a z-statistic, for details see Method section) 


\section{Discussion}

We began this article by developing a concise theoretical framework that conceived of the overarching "public sphere at large" of a polity as being comprised of a multiplicity of unequal (sub-)public spheres. We maintained that each of these sub-public spheres could be understood, and analytically delimited, as a specific set of participants (speakers/audiences) communicating in a specific communicative space in accordance with a specific set of discursive patterns. We suggested referring to such configurations as counterpublic spheres if they were characterized by discursive elements aimed either at (1) deconstructing power relationships within a superior public sphere, at (2) providing counterarguments that challenged the consensus within this superior public sphere, or at (3) strengthening the identity of the emergent counterpublic collective.

Within this theoretical framework, we then carried out an empirical analysis of the portrayal of the new anti-Euro party AfD in a variety of distinct public spheres, which we delimited at different points of the argument on the basis of the three criteria above. At a first level of analysis, we distinguished between two public spheres according to the communicative space within which they operated: (1) the news article sections of opinion-leading news websites and (2) the comment sections of these news websites. A qualitative framing analysis of the first public sphere, the news article sections, showed how Germany's most powerful journalists unanimously painted a rather dismissive picture of the new party. They did so by employing a limited number of issue-specific frames within seven emphasis frames.

With regard to the second public sphere (the comment sections), we found in a quantitative content analysis that, across all types of platform, roughly $75 \%$ of comments contained counterpublic elements. We thus argued that within this second public sphere a powerful counter (sub-)public sphere had emerged. Remarkably, approximately $75 \%$ of comments supported a new party that just days before only $4.7 \%$ of the electorate had voted for. In essence, these findings thus showcased how an emergent collective of counterpublic-minded individu- 


\section{RUNNING HEAD: PUBLIC SPHERES IN INTERACTION}

als were exploiting the comment sections of Germany's opinion-leading news websites in order to create a highly visible - and therefore enormously powerful - counterpublic sphere.

At a more abstract level, our findings can be seen as endorsing the central argument put forward in the introduction to this article: that comment sections, as these have been operating since the mid-2000s on the websites of many online mass-media outlets across Western democracies (Domingo et al., 2008; Reich, 2011; Thurman, 2008), are novel public spheres that are ideally configured - in terms of their specifics in relation to the three criteria of communicative space, participants, and discursive patterns - for powerful sub-counterpublic spheres to emerge within them. In particular, comment sections offer emerging counterpublic collectives one key opportunity (cf. Dahlberg, 2011, p. 862): that of contesting the discursive boundaries of mainstream public spheres and of breaking up the hegemonic structures of democratic “publics at large.” (Fraser, 1992, p. 124; Asen, 2000)

\section{Why Adopt Counterpublic Theory as an Alternative Theoretical Lens?}

The case study presented in this paper can be seen as vividly showcasing the benefits of opening up the academic debate on political talk in comment sections to normative frameworks other than deliberation theory. Had we adopted in our analysis standard indicators of deliberative discourse (cf. Freelon, 2013; Ruiz et al., 2011; Weber, 2014), our conclusions would have been both unspectacular and bleak. For instance, deliberation is typically associated with a vibrant exchange of arguments, which is often operationalized as interactivity (cf., for instance, Weber, 2014). However, in our data set, $67.7 \%$ of all commenters posted no more than one comment and $81.7 \%$ posted no more than two comments (Ruiz et al. [2011] and Weber [2014] report even lower levels of interactivity in their studies).

Secondly, deliberation is typically associated with discussants weighing different perspectives (cf. Ruiz et al., 2011). But in our data set only $2.5 \%$ of all comments contained elements of both mainstream and counterpublic discourse. By contrast, $94.8 \%$ of all comments supported exclusively one side. Viewpoint diversity within single comments was thus ex- 


\section{RUNNING HEAD: PUBLIC SPHERES IN INTERACTION}

tremely low. Thirdly, deliberation is frequently associated with the ideal of discussants changing their opinions and overcoming ideological divides (Dahlberg, 2011; Freelon, 2013). In our data set, however, only $2.7 \%$ of all commenters showed signs of changing their opinions, in the sense that they subsequently posted comments that fell on both sides of the divide. By contrast, the five most active users stuck staunchly to their beliefs, posting between 19 and 57 comments each -exclusively on one side of the divide.

Thus, had we adopted the theoretical lens of deliberation, we would most likely have found, as did previous studies (for literature overviews, consider Freelon, 2013; Ruiz et al., 2011), that political talk in our comment sections was overall of poor democratic quality, with minor differences between different news sites. However, quite obviously, we would thus have missed the very essence of the communicative phenomenon occurring within these novel digital spaces. While political commenting in our case study may have been of poor deliberative quality, it was arguably highly consequential for the formation of public opinion in Germany: directly beneath journalistic content published on Germany's opinion-leading online newspapers across the political spectrum, massive threads of user-generated comments appeared that were overwhelmingly dominated by commenters who were countering the consensual structures of mainstream mass-media reporting.

To summarize, three key differences between deliberation and counterpublic theory as analytical lenses for scrutinizing political talk in comment sections can be formulated. Firstly, a deliberative approach draws the researcher's attention to viewpoint diversity within single comments. By contrast, counterpublic theory draws the researcher's attention to structural diversities and dominant consensus structures of public spheres as a whole. Secondly, a deliberation perspective shifts the focus of analysis to the interaction between individual commenters. By contrast, a counterpublic approach shifts the focus of analysis to the interaction of two (or more) hierarchical public spheres. And, thirdly, deliberation theory looks for the (potentially positive) consequences of political commenting for democracy primarily in its impact 


\section{RUNNING HEAD: PUBLIC SPHERES IN INTERACTION}

on the attitudes and behaviour of individual participants/commenters. By contrast, counterpublic theory presumes that the (potentially positive) consequences of political talk in comment sections lie primarily in the impact of the emerging counterpublics on passive, noncommenting mass audiences and on changing discursive structures within the public at large.

\section{Factors Shaping Counterpublic Discourses in Comment Sections}

While this is the first study on comment sections to adopt counterpublic theory as a normative lens, a range of previous studies have explored within other normative frameworks how different factors impact commenting on mass-media websites. Factors found to predict the number of comments, for instance, included the topic of the article (Boczkowski \& Mitchelstein, 2012), the article's newsworthiness (Weber, 2014), and the overall level of "political activity" at the time of commenting (Boczkowski \& Mitchelstein, 2012). With regard to the actual content of comment sections, Ruiz et al. (2011) found, in a comparative study of five news websites across five nations, indications that comment sections of different deliberative quality emerged within different media systems.

The present study contributes to this literature in at least three respects. Firstly, our findings indicate that in cases like the one under investigation here (that is, those characterized by a hegemonic consensual structure within the mainstream public sphere), the political orientation of a news platform will strongly impact not only the level of commenting activity, but also the content of comments. Secondly, our findings showcase how commenters tend to resort to different strategies and styles of counterpublic commenting on tabloid and on nontabloid platforms. Finally, our research points to a third, preliminary hypothesis: that a hegemonic discursive configuration of mainstream media discourse (that is, a configuration that systematically disregards the views of a vocal minority on a specific issue) should be tested in future research as a key factor that can explain peaks of user participation in comment sections. While we could not test this hypothesis systematically in this study, all 22 articles included in our sample clearly appeared to be among the most commented upon on the nine 


\section{RUNNING HEAD: PUBLIC SPHERES IN INTERACTION}

platforms under investigation.

The conceptualization of public spheres developed in this article appears to be a promising tool for further investigation of the factors shaping discourses in comment sections, since it affords a holistic understanding of commenting on news websites: as performed by a specific set of participants (speakers/audiences) meeting in specific communicative spaces following specific sets of established discursive patterns. A first key advantage of this theoretical framework is that it allows a variety of public spheres to be neatly delimited, for heuristic purposes, and tested for differences and similarities between them (cf. the analysis in this article). Moreover, the approach encourages researchers not to limit their search for potentially influential factors to one of these three categories, but to at least ponder all three.

\section{Counterpublics in Comment Sections: Dangerous or Beneficial to Democracy?}

From a normative perspective, the question remains whether counterpublics emerging in comment sections should be viewed rather as beneficial or as detrimental to the democratic quality of publics at large. Within theories of agonistic democracy, the central democratic function of counterpublics is to expand discursive space and to mitigate "unjust participatory privileges enjoyed by members of dominant social groups.” (Fraser, 1992, p. 124; Downey \& Fenton, 2003; Mouffe, 1999) In our case study, the pro-AfD counter-discourses emerging in the comment sections clearly fostered this aim. While Euro-sceptic arguments, as advocated by the AfD, were largely absent from the public sphere of mainstream mass media, they were dominant in the subordinate, yet still highly visible, public sphere of comment sections.

However, there are also at least two possible dangers that could be associated with counterpublics emerging in comment sections. Firstly, comment sections could be exploited by social movements that bluntly oppose the basic values of free and democratic societies. Recent research has shown how blogs, forums and other digital spaces can be harnessed by, for instance, post-fascist movements claiming their "democratic right" to be "racist" (Cammaerts, 2009, p. 555). By comparison with blogs and forums, however, the danger that com- 


\section{RUNNING HEAD: PUBLIC SPHERES IN INTERACTION}

ment sections of mainstream media outlets will host anti-democratic discourses is rather limited, since these spaces are typically closely monitored by journalists (cf. Reich, 2011; Ruiz et al., 2011; Thurman, 2008). In our case study, for instance, a significant number of comments posted by AfD supporters were obviously deleted by moderators, possibly because they promoted racist or Nazi ideas. This suggests that comment sections, as communicative spaces, seem to be predestined to host a specific type of counterpublic sphere: those that propagate ideas which are systematically excluded from the mainstream mass media but, at the same time, remain within the realm of what is considered legal and broadly "sayable" within a given socio-political context. The case of the German anti-Euro party AfD represents an excellent example of a counterpublic operating on this narrow terrain at the margins of democratically legitimate public debate which is, however, crucial to any type of discursive change.

A second danger to democratic publics at large could be seen in the fact that counterpublics in comment sections create an image of public opinion that is strongly tilted towards counterpublic positions and thus systematically deviates from representative public opinion. In our case study, for instance, $75 \%$ of all comments were posted in support of a party that just days earlier only $4.7 \%$ of the electorate had voted for. Findings like these could be regarded as highly problematic, since recent research has shown that user-generated comments do significantly impact both readers' perceptions of public opinion and their personal opinions (Lee, 2012; Lee \& Jang, 2010). However, counterpublic theorists would probably not share such misgivings. In cases where mainstream media systematically discriminate against the views of minorities, counterpublic theorists would more likely view comment sections dominated by such minorities as a democratically legitimate means of partly offsetting "unjust participatory privileges" (Fraser, 1992, p. 124; cf. Dahlberg, 2011; Downey \& Fenton, 2003). To summarize, in Western democracies and from a counterpublic perspective, we can think of no compelling arguments against viewing counterpublic spheres, as they are likely to emerge in comment sections, as enriching and welcome additions to extant public spheres at large. 
RUNNING HEAD: PUBLIC SPHERES IN INTERACTION

\section{Promising Directions for Future Research: The Power of Commenters and Journalists}

Future research on counterpublics emerging in comment sections is highly relevant for at least two reasons. Firstly, comment sections can be expected to gain further in audience reach across the globe, with the number of news media offering this feature increasing (Domingo et al., 2008; Reich, 2011; Thurman, 2008; Ziegele \& Quiring, 2013). Secondly, we believe that the findings in the case study presented in this article are generalizable to a large number of high-profile issues and incidents in democratic life. These cases include not only coverage of marginalized domestic groups and minorities, for instance religious sects, but also coverage of international conflicts, for instance the reporting of the recent referendum in the Crimea. At the most general level, we would expect powerful counterpublics to emerge in comment sections in all cases where the mainstream mass media disregard the views of vocal minorities, given that these views remain broadly within the legal and cultural limits of what is publicly "sayable" in a specific socio-political context.

This case study has clear limitations that, however, open up a series of fascinating avenues for future research. Firstly, this study was not able to investigate the role that platform architectures play in the emergence of counterpublics (communicative space). Yet the shape of a counterpublic sphere as it appears to the reader may differ significantly depending on, for instance, whether a website presents user-generated comments sorted by "most popular first" or "newest first." Secondly, this study did not identify the strategies used by the most successful counterpublic commenters (discursive patterns). By contrast, future research could explore how specific characteristics of counterpublic comments impact their popularity. For instance, in our case study, one could ask whether one of the three discursive strategies for creating counterpublic discourse was particularly successful in generating "likes."

Thirdly, our study did not discuss systematically the power of journalists, who still have a range of options for shaping and containing counterpublics as they emerge in comment sections (participants). Aside from censoring single comments, journalists also have the power 


\section{RUNNING HEAD: PUBLIC SPHERES IN INTERACTION}

not to report on an issue, or not to report extensively (with the latter strategy apparently being pursued by left-leaning newspapers in our case study). If a news website does not cover an issue, it prevents virtual spaces for counterpublic discourses from opening up. Fourthly, we can assume that the content of journalistic articles impacts the shape of the counterpublics that emerge in the comments below them. For instance, it would be fascinating to investigate the degree to which emphasis frames presented in specific articles correlate with the frequency of emphasis frames used in comments posted on those articles. Finally, this study focused on just one case within one national context. In future research, it would be intriguing to trace mainstream and counterpublic spheres as they evolve in comment sections in the aftermath of global events, exploring the fascinating interaction of multiple public spheres as they cross and transcend both national and discursive boundaries.

\section{References}

Al-Saggaf, Y. (2006). The online public sphere in the Arab world: The war in Iraq on the Al Arabiya website. Journal of Computer-Mediated Communication, 12, 311-334. doi:10.1111/j.1083-6101.2006.00327.x

Arbeitsgemeinschaft Online Forschung (2013). Internet Facts 2013. Retrieved from http://www.agof.de/studienarchiv-internet-2013/\#2013-09

Asen, R. (2000). Seeking the "counter" in counterpublics. Communication Theory, 10, 424446. doi:10.1111/j.1468-2885.2000.tb00201.x

Boczkowski, P. J., \& Mitchelstein, E. (2012). How users take advantage of different forms of interactivity on online news sites: Clicking, e-mailing, and commenting. Human Communication Research, 38, 1-22. doi:10.1111/j.1468-2958.2011.01418.x

Breese, E. B. (2011). Mapping the variety of public spheres. Communication Theory, 21, 130-149. doi:10.1111/j.1468-2885.2011.01379.x

Cammaerts, B. (2009). Radical pluralism and free speech in online public spaces. The case of North Belgian extreme right discourses. International Journal of Cultural Studies, 12, 
RUNNING HEAD: PUBLIC SPHERES IN INTERACTION

555-575. doi:10.1177/1367877909342479

Cammaerts, B. (2012). Protest logics and the mediation opportunity structure. European Journal of Communication, 27, 117-134. doi:10.1177/0267323112441007

Dahlberg, L. (2007). Rethinking the fragmentation of the cyberpublic: From consensus to contestation. New Media \& Society, 9(5), 827-847. doi:10.1177/1461444807081228

Dahlberg, L. (2011). Re-constructing digital democracy: An outline of four "positions." New Media \& Society, 13, 855 -872. doi:10.1177/1461444810389569

Dahlgren, P. (2005). The internet, public spheres, and political communication: Dispersion and deliberation. Political Communication, 22(2), 147-162.

doi:10.1080/10584600590933160

Diakopoulos, N., \& Naaman, M. (2011). Towards quality discourse in online news comments. In Proceedings of the ACM 2011 Conference on Computer Supported Cooperative Work (pp. 133-142). Retrieved from http://dl.acm.org/citation.cfm?id=1958844

De Vreese, C. H. (2010). Framing the economy: Effects of journalistic news frames. In P. D’Angelo \& J. A. Kuypers (Eds.), Doing news framing analysis (pp. 187-214). New York: Routledge.

Domingo, D., Quandt, T., Heinonen, A., Paulussen, S., Singer, J. B., \& Vujnovic, M. (2008). Participatory journalism practices in the media and beyond. Journalism Practice, 2, 326-342. doi:10.1080/17512780802281065

Douai, A., \& Nofal, H. K. (2012). Commenting in the online Arab public sphere: Debating the Swiss minaret ban and the "Ground Zero Mosque" online. Journal of ComputerMediated Communication, 17, 266-282. doi:10.1111/j.1083-6101.2012.01573.x

Downey, J., \& Fenton, N. (2003). New media, counter publicity and the public sphere. New Media \& Society, 5, 185-202. doi:10.1177/1461444803005002003

Eveland, W. P., Morey, A. C., \& Hutchens, M. J. (2011). Beyond deliberation: New directions for the study of informal political conversation from a communication perspective. 
RUNNING HEAD: PUBLIC SPHERES IN INTERACTION

Journal of Communication, 61, 1082-1103. doi:10.1111/j.1460-2466.2011.01598.x

Fraser, N. (1992). Rethinking the public sphere: A contribution to the critique of actually existing democracy. In C. Calhoun (Ed.), Habermas and the public sphere (pp. 109-142). Cambridge, MA: MIT Press.

Freelon, D. (2010). Analyzing online political discussion using three models of democratic communication. New Media \& Society, 12, $1172-1190$.

doi:10.1177/1461444809357927

Freelon, D. (2013). Discourse architecture, ideology, and democratic norms in online political discussion. New Media \& Society. Advance online publication.

doi:10.1177/1461444813513259

Habermas, J. (1989). The structural transformation of the public sphere. Cambridge, MA: MIT Press. (Original work published 1962)

Lee, E.-J. (2012). That's not the way it is: How user-generated comments on the news affect perceived media bias. Journal of Computer-Mediated Communication, 18, 32-45. doi:10.1111/j.1083-6101.2012.01597.x

Lee, E.-J., \& Jang, Y. J. (2010). What do others' reactions to news on internet portal sites tell us? Effects of presentation format and readers' need for cognition on reality perception. Communication Research, 37, 825-846. doi:10.1177/0093650210376189

Lunt, P., \& Livingstone, S. (2013). Media studies' fascination with the concept of the public sphere: Critical reflections and emerging debates. Media, Culture \& Society, 35, 87-96. doi:10.1177/0163443712464562

McCluskey, M., \& Hmielowski, J. (2012). Opinion expression during social conflict: Comparing online reader comments and letters to the editor. Journalism, 13, 303-319. doi: $10.1177 / 1464884911421696$

Mitchelstein, E. (2011). Catharsis and community: Divergent motivations for audience participation in online newspapers and blogs. International Journal of Communication, 5, 
RUNNING HEAD: PUBLIC SPHERES IN INTERACTION

2014-2034.

Mouffe, C. (1999). Deliberative democracy or agonistic pluralism? Social Research, 66, 745758.

Neuendorf, K. A. (2002). The content analysis guidebook. London: Sage.

Nielsen, C. E. (2014). Coproduction or cohabitation: Are anonymous online comments on newspaper websites shaping news content? New Media \& Society, 16(3), 470-487. doi:10.1177/1461444813487958

Purcell, K., Rainie, L., Mitchell, A., Rosenstiel, T., \& Olmstead, K. (2010). Understanding the participatory news consumer. Retrieved from the Pew Internet Research Center website: http://www.pewinternet.org/2010/03/01/understanding-the-participatory-newsconsumer

Reich, Z. (2011). User comments. The transformation of participatory space. In J. B. Singer et al. (Eds.), Participatory journalism (pp. 96-117). Chichester, UK: Wiley-Blackwell.

Ruiz, C., Domingo, D., Micó, J. L., Díaz-Noci, J., Meso, K., \& Masip, P. (2011). Public sphere 2.0? The democratic qualities of citizen debates in online newspapers. The International Journal of Press/Politics, 16, 463-487. doi:10.1177/1940161211415849

Thurman, N. (2008). Forums for citizen journalists? Adoption of user generated content initiatives by online news media. New Media \& Society, 10, 139-157. doi: $10.1177 / 1461444807085325$

Van Gorp, B. (2010). Strategies to take subjectivity out of framing analysis. In P. D'Angelo \& J. A. Kuypers (Eds.), Doing News Framing Analysis (pp. 84-109). New York: Routledge.

Warner, M. (2002). Publics and Counterpublics. Public Culture, 14, 49-90.

Weber, P. (2014). Discussions in the comments section: Factors influencing participation and interactivity in online newspapers' reader comments. New Media \& Society, 16(6), 941957. doi:10.1177/1461444813495165 
RUNNING HEAD: PUBLIC SPHERES IN INTERACTION

Zhou, X., Chan, Y.-Y., \& Peng, Z.-M. (2008). Deliberativeness of online political discussion. Journalism Studies, 9, 759-770. doi:10.1080/14616700802207771

Ziegele, M., \& Quiring, O. (2013). Conceptualizing online discussion value. A multidimensional framework for analyzing user comments on mass-media websites. In E. L. Cohen (Ed.), Communication yearbook 37 (pp. 125-153). New York: Routledge. 